\title{
Linkage Disequilibrium and Haplotype Diversity in the Genes of the Renin-Angiotensin System: Findings From the Family Blood Pressure Program
}

\author{
Xiaofeng Zhu, ${ }^{1,4,5}$ Denise Yan, ${ }^{2,4}$ Richard S. Cooper, ${ }^{1}$ Amy Luke, ${ }^{1}$ Morna A. Ikeda, ${ }^{2}$ \\ Yen-Pei C. Chang, ${ }^{2}$ Alan Weder, ${ }^{3}$ and Aravinda Chakravarti ${ }^{2}$ \\ ${ }^{7}$ Department of Preventive Medicine and Epidemiology, Loyola Stritch School of Medicine, Maywood, Illinois 60153, USA; \\ ${ }^{2}$ McKusick-Nathans Institute of Genetic Medicine, Johns Hopkins University, Baltimore, Maryland 21287, USA; ${ }^{3}$ Division of \\ Hypertension, University of Michigan School of Medicine, Ann Arbor, Michigan 48109, USA
}

\begin{abstract}
Association studies of candidate genes with complex traits have generally used one or a few single nucleotide polymorphisms (SNPs), although variation in the extent of linkage disequilibrium (LD) within genes markedly influences the sensitivity and precision of association studies. The extent of LD and the underlying haplotype structure for most candidate genes are still unavailable. We sampled 193 blacks (African-Americans) and 160 whites (European-Americans) and estimated the intragenic LD and the haplotype structure in four genes of the renin-angiotensin system. We genotyped $25 \mathrm{SNPs}$, with all but one of the pairs spaced between 1 and $20 \mathrm{~kb}$, thus providing resolution at small scale. The pattern of LD within a gene was very heterogeneous. Using a robust method to define haplotype blocks, blocks of limited haplotype diversity were identified at each locus; between these blocks, LD was lost owing to the history of recombination events. As anticipated, there was less LD among blacks, the number of haplotypes was substantially larger, and shorter haplotype segments were found, compared with whites. These findings have implications for candidate-gene association studies and indicate that variation between populations of European and African origin in haplotype diversity is characteristic of most genes.
\end{abstract}

[The sequence data described in this paper are available in GenBank under the following accession nos: AGT, MIM 106150; Renin, MIM 179820; ACE, MIM 106180; Angiotensin receptor I, MIM 106165. Supplementary material is available online at http://www.genome.org.]

\begin{abstract}
The pattern of linkage disequilibrium (LD) at a locus has important implications for disease gene mapping using comparisons of allele frequencies in affected and unaffected individuals (Lander and Schork 1994; Jorde 2000; Risch 2000; Abecasis et al. 2001). Virtually all association studies conducted for complex phenotypes use only one marker, either a single nucleotide polymorphism (SNP) or an Alu element. The adequacy of this design depends critically on the extent of LD within the gene or region being investigated, and which SNP is used for analysis. The inability to take population-genetics architecture into account probably contributes to the inconsistent and disappointing results seen in complex-trait association studies.

Estimates of the extent of LD across the human genome vary considerably (Tishkoff et al. 1996; Kruglyak 1999; Dunning et al. 2000; Taillon-Miller et al. 2000; Abecasis et al. 2001; Reich et al. 2001). Substantial heterogeneity has been observed across various regions; many features, including biological and stochastic factors, likely contribute to this phenomenon (Taillon-Miller et al. 2000; Abecasis et al. 2001; Reich et al. 2001). Because LD also reflects the history of a population in terms of age and the number of founders, it

\footnotetext{
${ }^{4}$ These authors contributed equally to this work. ${ }^{5}$ Corresponding author. E-MAIL xzhu1@lumc.edu; FAX (708) 327-9009.

Article and publication are at http://www.genome.org/cgi/doi/10.1101/
} gr.302003. Article published online before print in January 2003.
\end{abstract}

would also be anticipated that different populations would have different patterns. In particular, shorter LDs and greater haplotype diversity have been seen in human African-origin populations (Chakravarti et al. 1984; Zhu et al. 2000; Reich et al. 2001). Reich et al. (2001) recently examined 19 randomly selected genomic regions spanning $160 \mathrm{~kb}$ in a sample of Swedes and Nigerians. Among Europeans, the half-length of LD, which is considered a useful minimum for association studies, was $60 \mathrm{~kb}$, whereas it was only $5 \mathrm{~kb}$ for the Africans (Reich et al. 2001). These results are consistent with the previous reports of greater genetic diversity among Africans, both at the level of individual polymorphisms and haplotypes (Cargill et al. 1999; Halushka et al. 1999; Rieder et al. 1999).

Recent investigations of global haplotype patterns demonstrate that pronounced haplotype structure on "blocks" exists in the human genome (Daly et al. 2001; Johnson et al. 2001; Patil et al. 2001). By considering haplotypes as the basic unit, rather than individual SNPs, Daly et al. (2001) found that LD is clearly a monotonic function of physical distance and that historical recombination is the major determinant of the breakdown in LD. This finding has important implications for association mapping. In a study of Crohn's disease, Rioux et al. (2001) successfully performed an association analysis using haplotype blocks and isolated a $250-\mathrm{kb}$ segment harboring the susceptibility locus from the original 18$\mathrm{cM}$ region.

The renin-angiotensin system (RAS) plays a critical 
physiological role in the cardiovascular system. The primary genes that comprise the RAS have, perhaps not surprisingly, been the focus of an enormous number of association studies over the last decade. Even though important genetic influences have been noted for the direct phenotype of some of the RAS genes, most notably angiotensin I-converting enzyme (ACE; Soubrier et al. 1994), their role as susceptibility or protective genes for cardiovascular disease is still unresolved (Fornage et al. 1998; O'Malley et al. 1999; Keavney et al. 2000; Zhu et al. 2000; Svetky et al. 2001). It is reasonable to assume that more detailed information about the organization of genetic variation at these loci will be required before the full impact of the RAS genes can be appreciated. The purpose of our study was to determine the LD distribution and haplotype structure in the RAS genes among individuals within and between populations by genotyping a set of SNPs in a community-based sample of U.S. whites (European-Americans) and blacks (African-Americans).

\section{RESULTS}

Our original data set includes 193 black families and 160 white families. Because the numbers of siblings in the two groups were comparable, we randomly selected one sibling from each family after excluding the probands. The genotyped siblings, thus selected, included 193 black and 160 white individuals. Five SNPs were genotyped in each of the four genes, with the exception of $A C E$, for which 10 SNPs were

Table 1. Genetic Polymorphisms in the RAS Genes, Whites and Blacks

\begin{tabular}{|c|c|c|c|c|c|c|}
\hline \multirow[b]{2}{*}{$\begin{array}{l}\text { Polymorphism } \\
\text { (minor allele) }^{a}\end{array}$} & \multirow[b]{2}{*}{ dbSNPb } & \multicolumn{2}{|c|}{ Whites } & \multicolumn{2}{|c|}{ Blacks } & \multirow[b]{2}{*}{$\delta_{c}$} \\
\hline & & $\begin{array}{l}\text { minor } \\
\text { allele freq. }\end{array}$ & $\begin{array}{c}\text { HWE } \\
P \text { value }\end{array}$ & $\begin{array}{l}\text { minor } \\
\text { allele freq. }\end{array}$ & $\begin{array}{c}\text { HWE } \\
P \text { value }\end{array}$ & \\
\hline \multicolumn{7}{|l|}{ REN } \\
\hline $\mathrm{C}-4021 \mathrm{~T}(\mathrm{~T})$ & & 0.12 & 0.24 & 0.28 & 0.29 & 0.16 \\
\hline $\mathrm{C}-3212 \mathrm{~T}(\mathrm{~T})$ & & 0.08 & 0.07 & 0.13 & 0.06 & 0.05 \\
\hline A4280C (C) & rs5705 & 0.12 & 1.0 & 0.30 & 0.08 & 0.18 \\
\hline G5795T (G) & rs5707 & 0.25 & 0.28 & 0.30 & 0.58 & 0.05 \\
\hline $\mathrm{C} 10377 \mathrm{~T}(\mathrm{~T})$ & & 0.12 & 0.23 & 0.18 & 0.63 & 0.06 \\
\hline \multicolumn{7}{|l|}{ AGTR1 } \\
\hline $\mathrm{A}-777 \mathrm{~T}(\mathrm{~A})$ & rs 275651 & 0.14 & 1.0 & 0.31 & 0.86 & 0.17 \\
\hline $\mathrm{G}-680 \mathrm{~T}$ (G) & rs 275652 & 0.14 & 0.2 & 0.26 & 0.18 & 0.12 \\
\hline A-119G (G) & rs 275653 & 0.15 & 0.35 & 0.26 & 0.14 & 0.11 \\
\hline C43732T (T) & rs5182 & 0.50 & 0.64 & 0.21 & 0.07 & 0.29 \\
\hline A44221G (G) & rs5183 & 0.05 & 1.0 & 0.33 & 0.32 & 0.28 \\
\hline \multicolumn{7}{|l|}{ AGT } \\
\hline C-532T (T) & rs5046 & 0.12 & 0.23 & 0.11 & 1.0 & 0.01 \\
\hline$A-217 G(A)$ & rs5049 & 0.13 & 0.27 & 0.26 & 0.85 & 0.13 \\
\hline$A-6 G(A)$ & rs5051 & 0.48 & 0.12 & 0.84 & 0.80 & 0.36 \\
\hline C3889T (C) & rs4762 & 0.11 & 1.0 & 0.09 & 0.64 & 0.02 \\
\hline C4072T (T) & rs699 & 0.48 & 0.71 & 0.15 & 0.36 & 0.33 \\
\hline \multicolumn{7}{|l|}{ ACE } \\
\hline $\mathrm{A}-239 \mathrm{~T}(\mathrm{~T})$ & rs4291 & 0.47 & 0.42 & 0.34 & 0.26 & 0.13 \\
\hline A7941G (G) & rs4318 & 0.05 & 0.001 & 0.20 & 0.11 & 0.15 \\
\hline C8342T (C) & rs4321 & 0.39 & 0.87 & 0.38 & 0.74 & 0.01 \\
\hline A10539G (A) & rs4335 & 0.40 & 0.52 & 0.74 & 1.0 & 0.34 \\
\hline A11599G (A) & rs4343 & 0.42 & 0.42 & 0.73 & 0.86 & 0.31 \\
\hline A12292G (A) & rs 4344 & 0.38 & 1.0 & 0.37 & 0.21 & 0.01 \\
\hline A15990G (G) & rs 4353 & 0.39 & 0.86 & 0.35 & 0.44 & 0.04 \\
\hline C17911T (C) & rs4359 & 0.38 & 0.74 & 0.55 & 0.87 & 0.17 \\
\hline C19329T (C) & rs4362 & 0.40 & 0.002 & 0.54 & 0.65 & 0.14 \\
\hline A20060G (A) & rs4363 & 0.39 & 1.0 & 0.55 & 0.56 & 0.16 \\
\hline
\end{tabular}

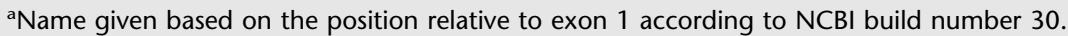
bSNP ID in database dbSNP. genotyped. The length of the genomic segments covered in each gene were, Renin $(R E N), 14 \mathrm{~kb}$; angiotensin receptor type I (AGTR1), $45 \mathrm{~kb}$; angiotensinogen (AGT), $4.5 \mathrm{~kb}$; and ACE, $21 \mathrm{~kb}$. In Table 1 the minor allele frequencies for the SNPs in the four genes are presented for both populations, along with $p$-values for the HWE test. The $\delta_{c}$ values for all the SNPs between whites and blacks are also presented in the last column. The minor allele frequencies were all $>10 \%$, with the exception of REN C-3212T, AGTR1 A44221G, and ACE A7941G in whites, and $A G T$ C3889T in blacks. No significant departure from HWE was found, except for ACE A7941G and ACE C19329T in whites. In general, blacks had a higher frequency of the alleles that were designated as minor among whites. To quantify the degree of population diversity, $F_{\mathrm{ST}}$ (Wright 1931), which is defined as the genetic variance among populations divided by the genetic variance within the total population, was calculated. Our data yielded a value for $F_{\mathrm{ST}}$ of 0.084 , with a $95 \%$ confidence interval of $(0.049,0.119)$ obtained by bootstrapping all sites (Weir 1996).

\section{Linkage Disequilibrium}

The most informative approach to defining LD would involve characterization of the haplotypes in each gene. Unfortunately, genotype information was missing for a number of SNPs, in particular for $A G T$. Therefore, we first examined pairwise LD measured by Lewontin's $D^{\prime}$ (Table 2). Because some entries in the 2-by-2 tables testing for $\mathrm{LD}$ were rare, we used Fisher's exact test to test the null hypothesis that $D^{\prime}=0$. The $p$-values were then adjusted by the number of SNP pairs in the gene using a Bonferroni correction, because pairwise LD tests within a gene were not independent. In Table 2 the shaded area indicates that significant LD exists within each gene after adjusting for multiple tests. The relevant findings are summarized separately for each gene below.

\section{REN}

In whites all observed $D^{\prime}$ values were equal to 1 , whereas this was true for only three of the $D^{\prime}$ values among blacks. As noted, when $D^{\prime}=1$, in the absence of intragenic recombination and repeated mutation, the maximum number of haplotypes that can be observed for a pair of SNPs is 3. These data therefore indicate an absence of intragenic recombination and repeated mutation in whites. In whites, LD among C-4021T, C-3212T, and C10377T was significant, but not with A4280C or G5795T. These results demonstrate that the LD test is not necessarily significant even when $D^{\prime}=1$. Except for G5795T, all the markers studied here had low minor allele frequencies. For SNPs with this distribution the test of LD may not have much power 
Table 2. Linkage Disequilibrium Statistic $\left(D^{\prime}\right)$ in RAS Genes in Whites (Lower Triangle) and Blacks (Upper Triangle)

\begin{tabular}{|c|c|c|c|c|c|c|c|c|c|c|}
\hline 1. REN & C-4021T & C-3212T & A4280C & G5795T & C10377T & & & & & \\
\hline C-4021T & - & 1.00 & 0.10 & 0.57 & 0.12 & & & & & \\
\hline $\mathrm{C}-3212 \mathrm{~T}$ & 1.00 & - & 1.0 & 0.73 & 1.0 & & & & & \\
\hline A4280C & 1.00 & 1.00 & - & 0.95 & 0.57 & & & & & \\
\hline G5795T & 1.00 & 1.00 & 1.00 & - & 0.02 & & & & & \\
\hline C10377T & 1.00 & 1.00 & 1.00 & 1.00 & - & & & & & \\
\hline 2. AGTR1 & A-777T & G-680T & A-119G & C43732T & A44221G & & & & & \\
\hline A-777T & - & 1.00 & 1.00 & 0.12 & 0.10 & & & & & \\
\hline G-680T & 1.00 & - & 1.00 & 0.09 & 0.10 & & & & & \\
\hline A-119G & 1.00 & 1.00 & - & 0.08 & 0.10 & & & & & \\
\hline C43732T & 0.13 & 0.03 & 0.10 & - & 1.00 & & & & & \\
\hline A44221G & 1.00 & 1.00 & 1.00 & 1.00 & - & & & & & \\
\hline 3. AGT & C-532T & A-217G & A- $6 \mathrm{C}$ & C3889T & C4072T & & & & & \\
\hline C-532T & - & 1.00 & 1.00 & 1.00 & 1.00 & & & & & \\
\hline$A-217 G$ & 1.00 & - & 1.00 & 1.00 & 1.00 & & & & & \\
\hline$A-6 \mathrm{G}$ & 1.00 & 1.00 & - & 1.00 & 1.00 & & & & & \\
\hline C3889T & 1.00 & 1.00 & 1.00 & - & 0.93 & & & & & \\
\hline $\mathrm{C} 4072 \mathrm{~T}$ & 0.87 & 0.87 & 0.96 & 1.00 & - & & & & & \\
\hline 4. ACE & A-239T & A7941C & C8342T & A10593G & A11599G & A12292C & A15990G & C17911T & C19329T & A20060C \\
\hline A-239T & - & 0.42 & 0.30 & 0.26 & 0.24 & 0.29 & 0.27 & 0.33 & 0.19 & 0.33 \\
\hline A7941G & 0.50 & - & 0.80 & 1.00 & 1.00 & 1.00 & 0.93 & 0.79 & 0.72 & 0.76 \\
\hline C8342T & 0.96 & 0.43 & - & 1.00 & 0.96 & 0.95 & 0.95 & 0.81 & 0.62 & 0.70 \\
\hline A10593G & 0.98 & 0.41 & 0.99 & - & 1.00 & 1.00 & 1.00 & 0.98 & 0.83 & 1.00 \\
\hline A11599G & 0.94 & 0.27 & 0.97 & 0.99 & - & 0.96 & 0.96 & 0.96 & 0.81 & 0.98 \\
\hline A12292G & 0.98 & 0.44 & 0.99 & 1.00 & 0.99 & - & 0.96 & 0.82 & 0.62 & 0.71 \\
\hline A15990G & 0.96 & 0.42 & 0.99 & 0.99 & 0.97 & 1.00 & - & 1.00 & 0.74 & 0.89 \\
\hline C17911T & 0.98 & 0.44 & 1.00 & 1.00 & 0.99 & 1.00 & 1.00 & - & 0.85 & 0.88 \\
\hline C19329T & 0.92 & 0.42 & 0.99 & 1.00 & 0.99 & 1.00 & 1.00 & 1.00 & - & 0.82 \\
\hline A20060G & 0.96 & 0.44 & 0.97 & 0.99 & 0.97 & 0.99 & 1.00 & 1.00 & 1.00 & 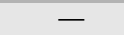 \\
\hline
\end{tabular}

Shaded area indicates statistical significance $(p<0.0001)$ after adjusting for multiple tests.

(Thompson et al. 1988). In blacks significant LD occurred between C-4021T and C-3212T, and between A4280C and G5795T, C10377T. Overall, therefore, considerable LD exists in this gene among whites, but much less occurs among blacks.

\section{AGTR1}

In the AGTR 1 gene, two LD clusters, separated by $44 \mathrm{~kb}$, were observed for both whites and blacks. One cluster consisted of the SNPs A-777T, G-680T, and A-119G, and the other consisted of C43732T and A44221G. Within these clusters all the $D^{\prime}$ values were equal to 1 , but $L D$ was weak between them, indicating frequent recombination events.

AGT

At the $A G T$ locus the $D^{\prime}$ values were $>0.8$ for both the black and the white samples. Seven of the 10 pairwise $D^{\prime}$ estimates in whites and 9 of 10 in blacks were equal to 1 , leading us to conclude neither recombination nor multiple mutations are present in both whites and blacks. Eight of the 10 and 3 of the 10 pairwise tests were statistically significant in whites and blacks, respectively. Significant LD was only observed between neighboring SNPs in blacks. In both populations C3889T was not in significant LD with any of the other SNPs, except for A-6G in whites. The minor allele T for C3889T had a low frequency in both whites and blacks.
$A C E$

For $A C E$, all the $D^{\prime}$ values were $>0.9$ in whites, yielding significant LD, except for A7941G, which had a minor allele A frequency of $5 \%$ in whites. In blacks, all the $D^{\prime}$ values were $>0.6$ except for some associated with A-239T. Significant LD was also found among all markers except A-239T.

To provide an overall estimate of $L D$ versus distance, we plotted both $D^{\prime}$ and $r^{2}$ against distance for the two groups (Fig. 1). LD decays as distance increases independent of the measure in blacks. However, LD decays much slower in whites than that in blacks, probably because of the short region considered. The pronounced contrast by racial group is likewise apparent in this graphical format.

\section{Haplotype Analysis}

We next defined the haplotypes and estimated their corresponding frequencies using the computer program PHASE. Stable estimates were obtained using 10,000 burn-in cycles and 10,000 iterations (see Supplementary Tables 1-4 available online at http://www.genome.org). The number of haplotypes among blacks was greater except for $A G T$, and haplotypes shared in both populations account for $90 \%$ of those occurring in whites, but much less in blacks. The frequencies of those haplotypes occurring only in whites were $7.1 \%$ for $A C E, 1.5 \%$ for $A G T R 1,8.1 \%$ for $R E N$, and $3.3 \%$ for $A G T$. The 
Zhu et al.

number of major haplotypes (frequency $\geqq 4 \%$ ) in whites was less than among blacks. To obtain the global LD for each of the 4 genes we performed simulation tests (Blanton and Chakravarti 1987; Antonarakis et al. 1988). We estimated the distribution of the number of different haplotypes under the assumption of random association of the SNPs within a gene when all of the observed chromosomes were sampled. Table 3 presents these results based on 1000 replications. The first column represents the candidate genes, and columns 2 to 5 present the number of chromosomes observed, the number of different haplotypes inferred by PHASE, the average number of haplotypes by simulations, and the minimum number of haplotypes by simulations in whites, respectively. Similar results in blacks appear in columns 6 through 9. In each of the four genes, the observed number of haplotypes was less than the minimum number simulated under the random association assumption. These results imply that the empirical $p$-values of global LD tests are $<0.001$, leading to the conclusion that strong global LD exists within all four genes.

\section{Haplotype Blocks}

Using the definition provided in Methods, we defined the haplotype blocks in the four genes. Table 4 displays the haplotypes and the corresponding frequencies in blocks. The solid lines between two blocks indicate that $>4 \%$ of all chromosomes are observed. One haplotype block for REN in whites was defined with four major haplotypes. To represent them, A4280C, G5795T, and only one of the three markers (C-4021T, C-3212T, and C10377T), are required, because the latter set are in complete LD. In contrast, two similar blocks were defined in blacks, one consisting of C-4021T and C-3212T and the other consisting of A4280C and G5795T. The SNP C10377T does not fall into either block. All four SNPs are necessary to represent the two blocks. Surprisingly, to represent most of the haplotypes (frequency $\geqq 4 \%$ ) in this gene for blacks, all five SNPs are required, although the genomic segment covered is only $14 \mathrm{~kb}$ long. When we considered each block as a locus and the haplotypes as the corresponding alleles, we obtained the $\delta_{c}$ values of 0.16 and 0.22 for these two blocks. We also found that the $\delta_{\mathrm{c}}$ value for a block is greater than the $\delta_{\mathrm{c}}$ values for the SNPs within the block.

In the AGTR1 gene, there are two blocks for both whites and blacks, with one block consisting of A-777T, G-680T, and A-119G, and the other including markers C43732T and

\section{Blacks}
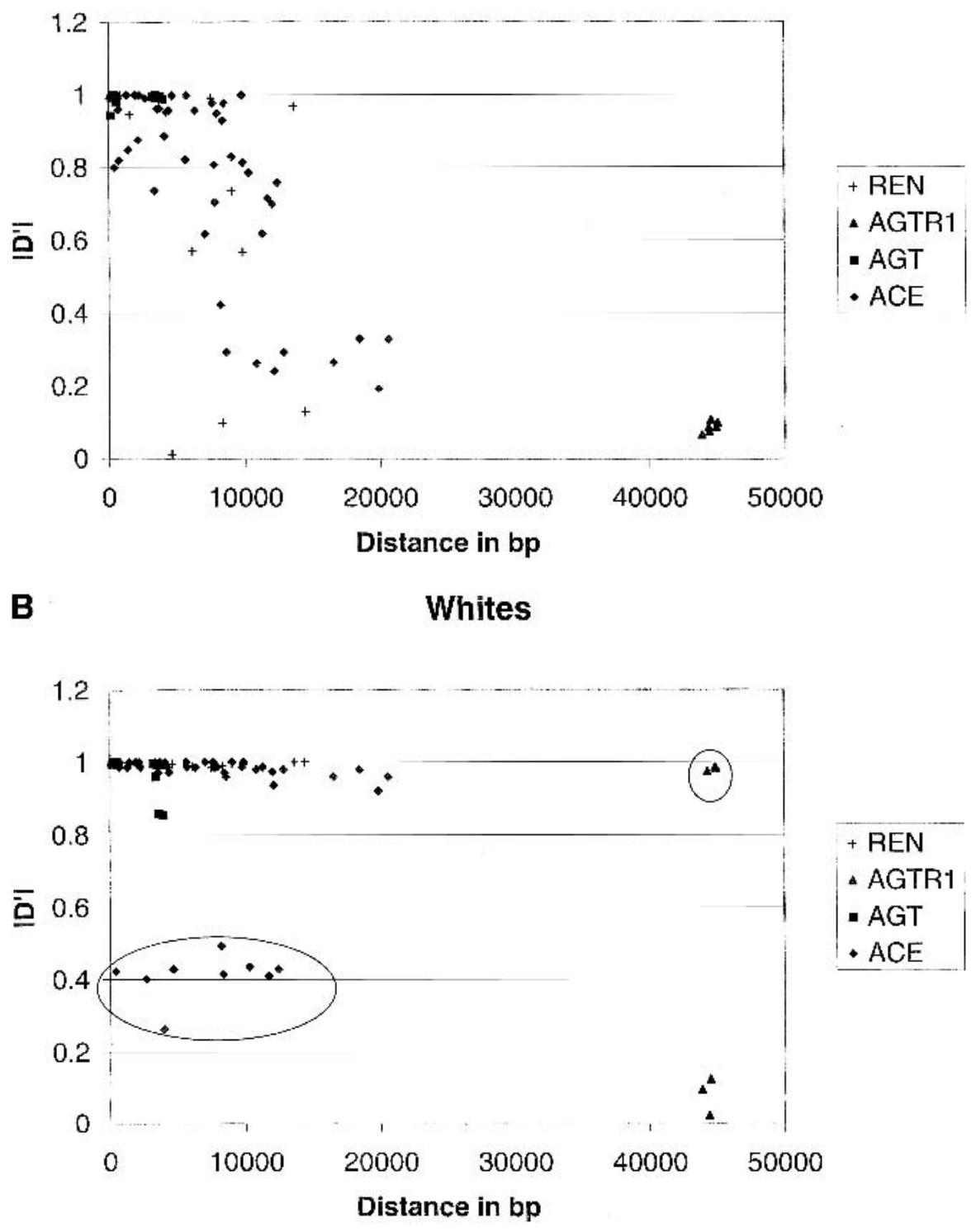

Figure 1 (Continued on next page)
A44221G. For both whites and blacks, any one of A-777T, G-680T, and A-119G can represent the first block. In the second block, only C43732T is necessary to represent this block in whites, but both C43732T and A44221G are required for blacks. The $\delta_{c}$ values we obtained for these two blocks were 0.17 and 0.29 . Similar to the Renin gene, the $\delta_{c}$ value for a block is not less than the $\delta_{\mathrm{c}}$ values for the SNPs within the block in this gene.

In $A G T$ there is one block that can be defined in both whites and blacks. AGT C3889T and one SNP from each of the two pairs C-532T/A-217G or A-6G/C4072T are necessary to represent the four major haplotypes in whites. However, to represent the five major haplotypes in blacks, both C-532T and $\mathrm{A}-217 \mathrm{G}$ must be included. Considering this block as a locus, we obtained the $\delta_{c}$ value 0.43 , which is greater than the $\delta_{c}$ values of all five SNPs. 
C Blacks
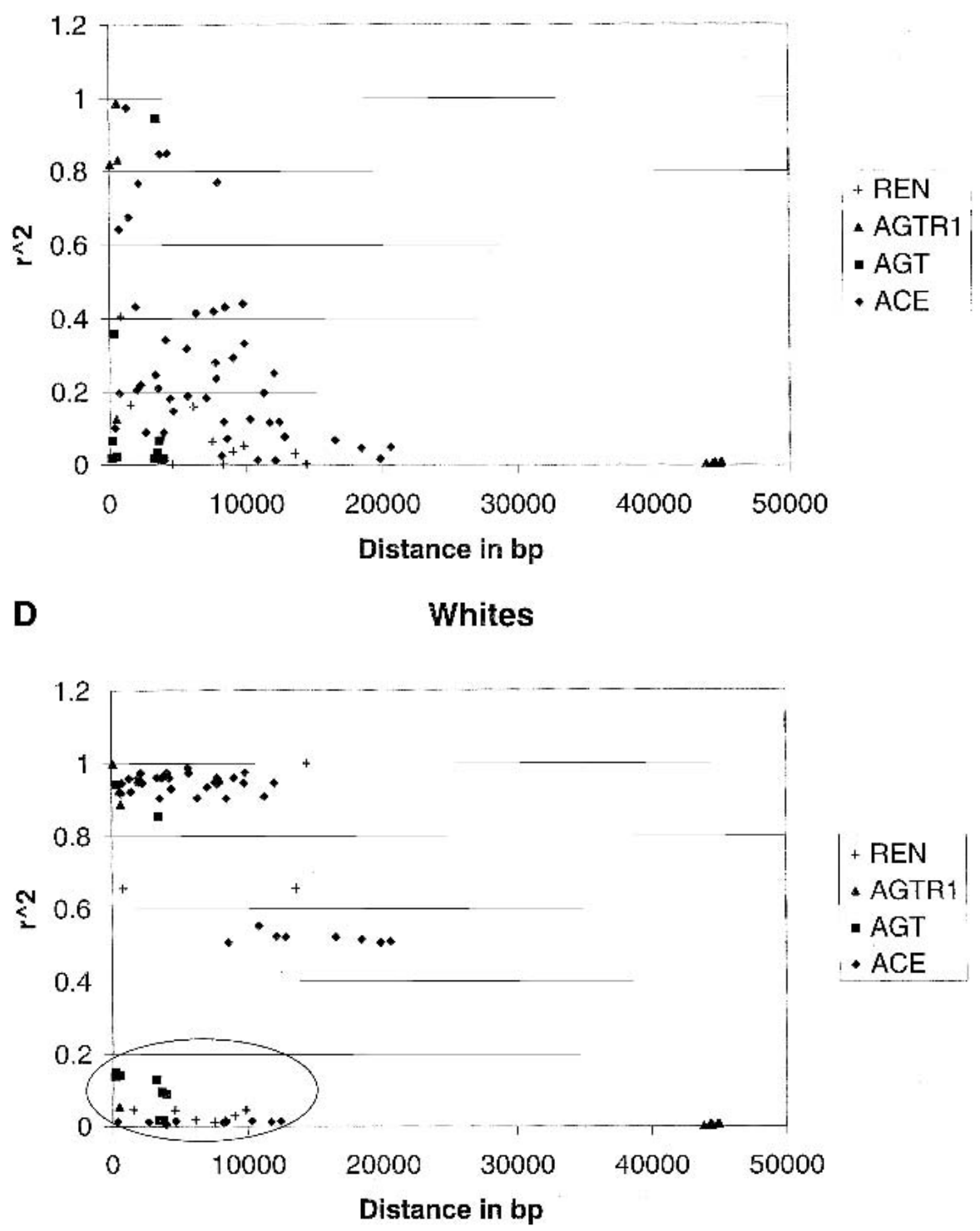

Figure 1 Comparison of LD between blacks and whites based on $D^{\prime}$ and $r^{2}$. (A) $\left|D^{\prime}\right|$ for blacks. (B) $\left|D^{\prime}\right|$ for whites. $(C) r^{2}$ for blacks. $(D) r^{2}$ for whites. In blacks, both $D^{\prime}$ and $r^{2}$ decay as the distance increases, although considerable variation is observed. In whites, the decay of $D^{\prime}$ values demarcated by the ellipse are apparently owing to the effects of rare minor allele frequency $(A C E A 7941 \mathrm{G}, f(G)=0.05)$. The rare minor allele frequency $(A G T R 1 \mathrm{~A} 44221 \mathrm{G}, f(\mathrm{G})=0.05)$ is also associated with $D^{\prime}$ values of 1 , as indicated in the circle. Excluding the $D^{\prime}$ values in the ellipse and the circle leads to a slower decay of the $D^{\prime}$ value in whites as the distance increases than that in blacks. Similarly, the low $r^{2}$ values in the ellipse among whites are caused by the minor alleles being rare. These $r^{2}$ values are derived from at least one SNP with an allele frequency $<0.15$. After excluding these values, $r^{2}$ decays as the distance increases.

in this block. Three SNPs, namely, A7941G, one of A10593G and A11599G, and one of C8342T, A12292G, and A15990G are required to represent the four major haplotypes. Considering this block as a locus, we obtained the $\delta_{\mathrm{c}}$ value 0.47 , which is greater than the $\delta_{c}$ values of all nine SNPs.

By defining DNA segments in this fashion, LD within a block is virtually complete, with historical recombination or repeated mutation at their margins. We consistently observed that haplotype blocks were shorter among blacks and consisted of a subset of the SNPs from the blocks in whites. It is also interesting to note that when the haplotypes were considered as the alleles there was much more heterozygosity, and therefore more information derived from the samples than could be obtained from typing single SNPs. To verify the consistency of these results we conducted similar analyses for a data set that included one parent from each family, and the results were essentially the same.

\section{DISCUSSION}

Our analysis makes possible a detailed description of the genomic organization of a sample of important cardiovascular candidate genes in two populations with contrasting levels of diversity. Although the number of SNPs we studied is relatively small, the sample size is large, compared with more recent genomic analyses, and the data presented here permit several conclusions. The primary source of heterogeneity in terms of the LD was observed between the two populations. Among whites very little historical recombination can be detected in the RAS genes, and only the SNPs at the AGTR1 gene, which were spaced at $45 \mathrm{~kb}$, show LD clusters that defined two haplotype blocks, with an interval of substantially decreased LD between these two sections. Among blacks, on the

In the $A C E$ gene, all the SNPs define one block in whites. Only two SNPs, namely, A-239T and any other SNP except A7941G are required to represent most haplotypes. In blacks, our definition also identifies a block including A7941G, C8342T, A10593G, A11599G, A12292G, A15990G, C17911T, C19329T, and A20060G. However, A-239T does not fall within this block because the haplotype distribution exceeds the 95\% bootstrap confidence interval after adding this SNP. The four major haplotypes only account for $76 \%$ of the total other hand, LD was weaker than among whites, except for $A G T$, for which the LD in blacks and whites was similar. The explanation for the similar LD in $A G T$ among blacks and whites may be that a small region in this gene has been examined, with the largest distance between two markers being $<4 \mathrm{~kb}$. Although population admixture may change the LD pattern, with the small difference in allele frequencies and such a short distance, it would be unlikely to have a major effect. More haplotypes are also observed in blacks, with the 
Zhu et al.

Table 3. Simulation Results for Testing for the Global LD in the RAS Genes

\begin{tabular}{|c|c|c|c|c|c|c|c|c|}
\hline & \multicolumn{4}{|c|}{ Whites } & \multicolumn{4}{|c|}{ Blacks } \\
\hline & \multirow[b]{2}{*}{ no. of $\mathrm{Chr}$} & \multicolumn{3}{|c|}{ no. of haplotypes } & \multirow[b]{2}{*}{ no. of Chr } & \multicolumn{3}{|c|}{ no. of haplotypes } \\
\hline & & observed & expected $^{a}$ & minimum no. & & observed & expected $^{a}$ & minimum no. \\
\hline REN & 320 & 5 & 20 & 15 & 378 & 13 & 28 & 23 \\
\hline AGTR1 & 202 & 6 & 18 & 13 & 340 & 9 & 30 & 24 \\
\hline AGT & 214 & 8 & 22 & 16 & 138 & 6 & 17 & 11 \\
\hline $\mathrm{ACE}$ & 286 & 14 & 209 & 190 & 362 & 31 & 249 & 221 \\
\hline
\end{tabular}

exception of the $A G T$ gene, for which the reverse was true. However, in $A G T$ there are five major haplotypes in blacks, but only four in whites. Among whites, there was one block observed in ACE, AGT, and REN, and two in the AGTR1 receptor. However, among blacks more haplotype blocks could be defined. These findings in whites are consistent with recent reports (Daly et al. 2001; Patil et al. 2001), which concluded that haplotype blocks range from $10-100 \mathrm{~kb}$ in European-derived populations. Our study also indicates that the African populations have much shorter haplotype blocks. The clustering of blocks also indicates local hotspots of recombination (Chakravarti et al. 1984; Clark et al. 1998; Templeton et al. 2000; Jeffreys et al. 2001). Taken together, these haplotype analyses clearly demonstrate that blacks have more haplotype diversity at these loci than do persons of European descent. The pairwise LD analysis is also consistent with this result. Within a block, three or four haplotypes will usually account for $>90 \%$ of the total haplotypes. Based on these findings, we were able to select fewer SNPs to represent most of the haplotypes within a block.

We also defined haplotype blocks by using the method of Daly et al. (2001). The differences of defining haplotype blocks by these two methods occurred only in the REN and $A C E$ genes in blacks. In REN, the method by Daly and colleagues defines two blocks, with the second block including SNPs A4280C, G5795T, and C10377T; in ACE, it defines two blocks, with the second block including C19329T and A20060G. However, the score statistics of the blocks, defined by the ratio of haplotypic heterozygosity and expected haplotypic heterozygosity (Daly et al. 2001), are not significantly different from that of blocks defined in our method, indicating that the differences may be due to the sampling variation. Thus, the haplotype blocks defined in these two methods are essentially the same.

Confidence in the generalizability of our findings is reinforced by their congruence with previous reports. Whether based on single genes (Halushka et al. 1999; Zhu et al. 2000) or random genomic segments (Reich et al. 2001), the relevant published data are similar in every respect to our findings. Even though they used very different sampling methods to choose genomic regions and markers, Reich et al. (2001) report estimates of LD half-length similar to ours, namely, $5 \mathrm{~kb}$ for blacks. Our findings therefore extend the observation of short LD to persons of African descent in the Western Hemisphere. Although the confidence limits on the estimated LD half-lengths have not been well defined, the similarity of the finding among U.S. blacks and Nigerians indicates that recent population admixture in the U.S. has not noticeably increased the extent of LD when we deal with a genomic distance $<45 \mathrm{~kb}$.

Variation in the extent of LD among human populations has obvious implications for gene mapping (Tishkoff et al. 1996; Wright et al. 1999; Taillon-Miller et al. 2000; Abecasis et al. 2001; Reich et al. 2001). Jorde (2000) has drawn attention to the possibility that a two-tiered strategy would be most efficient for association studies. If the aim is to localize a genetic effect within a 50-100-kb range, then European populations might be targeted; on the other hand, to carry out fine-mapping at the $1-5-\mathrm{kb}$ range, a study of African-origin groups would be more productive. We recently demonstrated the practical significance of this observation in a study localizing the 3 ' region within the ACE gene that has the greatest influence on ACE plasma activity (Zhu et al. 2000). In Jamaicans the effect could be resolved to a small region; however, in Germans, given the limited number of recombination events that were available to study, localization was not possible (Zhu et al. 2000). Similarly, using 13 markers in ACE in a Nigerian sample, we were able to identify a second 5 ' region that influenced plasma activity and use this information to find an association with blood pressure (Zhu et al. 2001). Using all the segregating variability expressed in populations of African ancestry, Zhu et al. (2001) demonstrated the limitations of the much-studied Alu motif in $A C E$ as a marker of susceptibility. This experience, if it can be generalized, indicates that association studies can become more informative if the appropriate target population is chosen and the entire store of genetic information at the target locus is fully exploited.

Our estimates of $\delta_{\mathrm{c}}$ values indicate that defining haplotype blocks could increase the $\delta_{\mathrm{c}}$ values, thereby increasing the power to detect LD in an admixed population. With the availability of abundant SNPs across the human genome (Sachidanandam et al. 2001), we should be able to define the necessary haplotype blocks (Daly et al. 2001; Patil et al. 2001). It might, therefore, be possible to select dense blocks with maximum haplotype frequency differences between two founder populations to conduct genome-wide admixture mapping.

Several limitations of this study must be acknowledged. The SNPs were chosen on the basis of frequency and the available published information, but we have no way to evaluate whether this introduced a bias. However, with the large sample size and the replication of the results by selecting one parent from each family, such bias should be negligible. Although the probands for this study were identified based on blood pressure near the upper $15 \%$, the age-gender-specific 
Table 4. Blocks and Haplotype Frequencies Within a Block in the RAS Genes

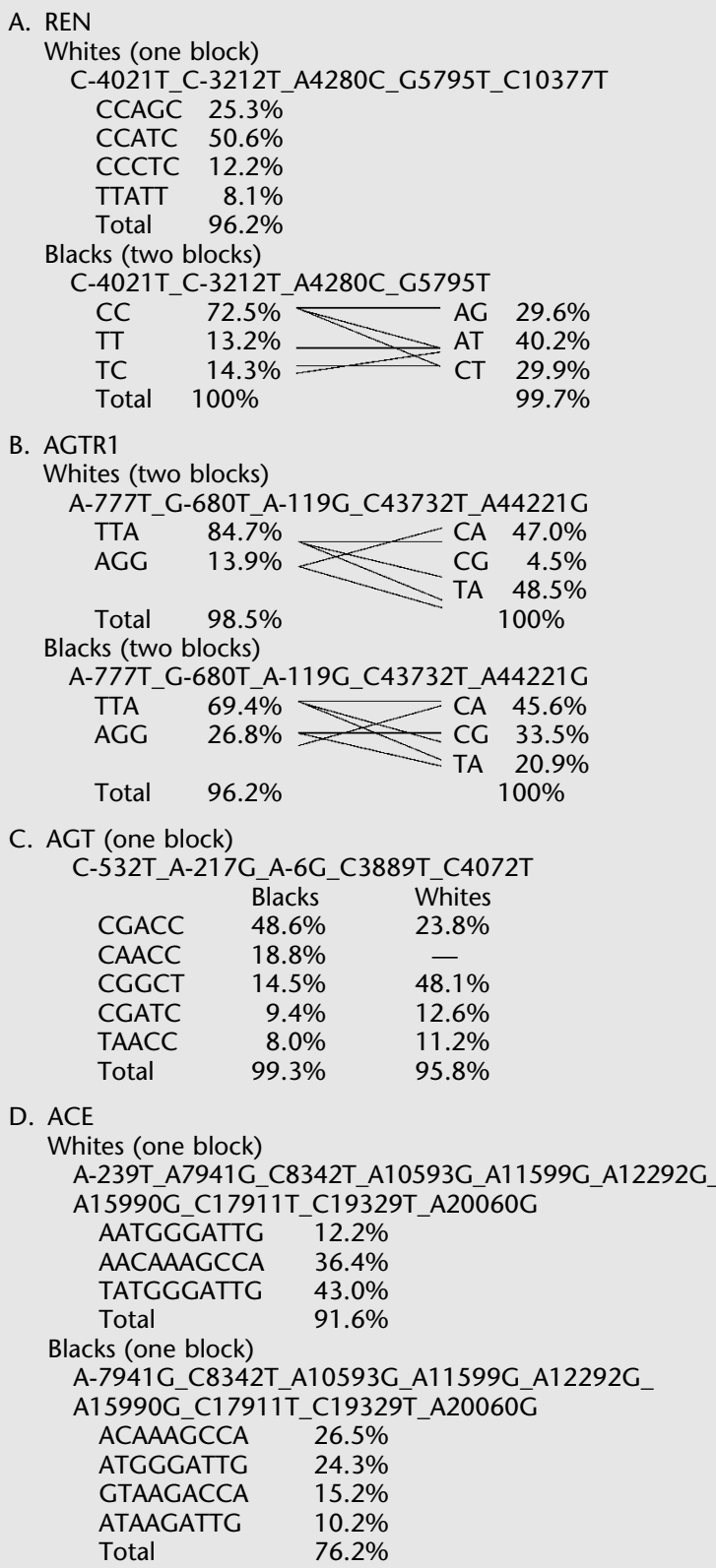

Lines indicate that the combined haplotype frequencies of two blocks are $>4 \%$ of all chromosomes.

distribution, our analysis sample excluded all the probands. Furthermore, our sampling method is unlikely to influence the patterns of $\mathrm{LD}$, because the variation of blood pressure explained by this region is very small (Zhu et al. 2001).

It seems reasonable to suggest that the complexity of genomic organization has been underestimated in most association studies of complex traits. Multiple variants, both in coding and promoter sequences, may well have complementary small effects. If this is true for most genes, more exhaustive search methods will be required than have been used.
Defining the haplotype blocks in the region of interest may be the necessary first step to avoid the "hit or miss" approach that characterizes mapping based on single SNPs.

\section{METHODS}

\section{Selection of Participants}

The participants in this study were enrolled in the GenNet component of the NHLBI-sponsored Family Blood Pressure Program (Province et al. 2000); the design and sampling procedures are to be published (B.A. Thiel, A. Chakravarti, R.S. Cooper, A. Luke, S. Lewis, A. Lynn, H. Tiwari, N.J. Schork, A.B. Weder, unpubl.). In brief, sibships including persons between the ages of 25 and 40 were enrolled if their systolic (SBP) or diastolic (DBP) blood pressures were in the upper 25th and 15 th percentile for black or white, respectively. AfricanAmericans were recruited in Maywood, Illinois, whereas persons of European descent were enrolled in Tecumseh, Michigan; ethnic classification was based on self-identification. The protocols were reviewed and approved by the review boards of the respective institutions. The original sample included 616 individuals from 201 black families in Maywood, and 618 individuals from 160 white families in Tecumseh. Our analysis focused on a sibling set consisting of one sibling randomly selected from each family, after excluding the proband. This sampling scheme should reduce the bias due to the ascertainment. The siblings chosen included 193 blacks and 160 whites.

\section{Laboratory Methods}

\section{SNPs of the Renin-Angiotensin System}

The candidate genes studied were REN (MIM 179820), AGTR1 (MIM 106165), AGT (MIM 106150), and ACE (MIM 106180) (http://www.ncbi.nlm.nih.gov/Omim). A total of 25 SNPs were genotyped. Because the human genomic sequences are still being refined, the position of an SNP within a gene may be different from previous publications. We named an SNP based on its position relative to the first base of exon 1 (according to the NCBI human genome sequence build 30) and also gave its corresponding reference SNP identification numbers (rs\#; Table 1). The cytogenetic map, polymorphic sites, and location of the SNPs for the REN, AGTR1, and AGT genes used in this study are shown in Table 5. The 10 ACE SNPs were obtained from Rieder et al. (1999).

\section{DNA Isolation}

DNA from buffy coat samples was extracted using the Puregene commercial kit, which combines cell lysis and protein precipitation (Gentra System, Inc.). DNA concentration was assessed by a Tecan GENIos Fluorometer using Picogreen.

\section{Genotyping}

The PrimerExpress software was used to design probes and primers, and a $5^{\prime}$ nuclease allelic discrimination Taqman assay was used for SNP genotyping (Perkin-Elmer Biosystems). The assay includes two fluorescent Taqman oligonucleotide probes: an allele 1-specific probe labeled with VIC and an allele 2-specific probe labeled with FAM (6-carboxyfluorescein). The VIC or FAM reporter dye is covalently attached to the 5 '-terminal base of the probe, and a nonfluorescent quencher dye, TAMRA (6-carboxy-tetramethylrhodamine), is attached at the $3^{\prime}$ end. Each $25-\mu \mathrm{L}$ PCR reaction contained 50 ng of genomic DNA, $900 \mathrm{nM}$ each PCR primer (Research Genetics), $200 \mathrm{nM}$ each probe, and Taqman Universal PCR Master Mix (a solution containing AmpErase Uracil- $N$-glycosylase (UNG), deoxyribonucleotides, uridine, passive reference dye (ROX), TaqGold DNA polymerase, and reaction buffer (Applied Biosystems P/N 4316033). Amplifications were per- 
Zhu et al.

\begin{tabular}{|c|c|c|c|c|}
\hline Gene & Cytogenetic map & Polymorphisms & Location in gene & Reference \\
\hline \multirow[t]{5}{*}{ REN } & $1 q 32$ & $\mathrm{C}-4021 \mathrm{~T}$ & Promotor & See Supplementary Fig. 1 \\
\hline & & $\mathrm{C}-3212 \mathrm{~T}$ & Promoter & See Supplementary Fig. 1 \\
\hline & & A4280C & Exon 2 & Halushka et al. 1999 \\
\hline & & G5795T & Intron 4 & Halushka et al. 1999 \\
\hline & & C10377T & Intron 8 & See Supplementary Fig. 1 \\
\hline \multirow[t]{5}{*}{ AGTR1 } & $3 q 21-q 25$ & A-777T & Promoter & Erdmann et al. 1999 \\
\hline & & G-680T & Promoter & Erdmann et al. 1999 \\
\hline & & A-119G & Promoter & Erdmann et al. 1999 \\
\hline & & $\mathrm{T} 43732 \mathrm{C}$ & Exon 5 & Bonnardeaux et al. 1994 \\
\hline & & A44221G & Exon 5 & Bonnardeaux et al. 1994 \\
\hline \multirow[t]{5}{*}{ AGT } & $1 q 42-q 43$ & C-532T & Promoter & Halushka et al. 1999 \\
\hline & & C-217T & Promoter & Halushka et al. 1999 \\
\hline & & $A-6 C$ & Promoter & Inoue et al. 1997 \\
\hline & & С3889T(T174M) & Exon 2 & Jeunemaitre et al. 1992 \\
\hline & & C4072T(M235T) & Exon 2 & Jeunemaitre et al. 1992 \\
\hline
\end{tabular}

$$
\delta_{c}=\frac{1}{2} \sum_{i=1}^{n}\left|f_{i 1}-f_{i 2}\right|
$$

where $f_{i 1}$ and $f_{i 2}$ are the frequencies of the $i$-th allele in two populations. The magnitude of $\delta_{c}$ is the principal determinant of the efficiency for admixture mapping (Chakraborty and Weiss 1988; Chakraborty et al. 1991). We first calculated the $\delta_{c}$ value for each SNP and next the $\delta_{c}$ values for a block by considering block haplotypes as alleles.

\section{ACKNOWLEDGMENTS}

We thank Hongyu Zhao for helpful comments. We thank Donghui Kan for his assistance in programming. This work was supported by grants from the National Heart, Lung and Blood Institute (UOI-HL54485; HL54466; HL65702)

formed under the following conditions: $50^{\circ} \mathrm{C}$ for $2 \mathrm{~min}$ for AmpErase UNG degradation of any carryover DNA, followed by AmpliTaq Gold enzyme activation at $95^{\circ} \mathrm{C}$ for $10 \mathrm{~min}$ before 40 cycles of $95^{\circ} \mathrm{C}$ for $15 \mathrm{sec}$ and $62^{\circ} \mathrm{C}$ for $1 \mathrm{~min}$ in a PTC-225 DNA Engine Tetrad thermal cycler (MJ Reseach). Fluorescence in each well was measured after PCR using the ABI Prism 7700 Sequence Detector System (SDS, PE Biosystems).

\section{Statistical Analysis}

Allele frequencies for each SNP were calculated by allele counting, and the Hardy-Weinberg equilibrium was tested using the $\chi^{2}$ test with $1 \mathrm{df}$. Pairwise LD was measured by $D^{\prime}$ (Lowontin 1964) and $r^{2}$ (Hill and Robertson 1968) within each ethnic sample. Pairwise LD was tested by Fisher's exact test (Chakravarti et al. 1984). For each gene, haplotypes were reconstructed using the computer progran PHASE (Stephens et al. 2001). PHASE uses Gibbs sampling to estimate the posterior probabilities of an individual's haplotypes given the observed genotypes, and thereby assigns haplotype phases. A global test of LD was performed according to the simulation method of Blanton and Chakravarti (1987), in which the observed number of haplotypes was compared with the simulated number of haplotypes under the assumption of linkage equilibrium (Antonarakis et al. 1988).

We defined a block as a DNA region in which there was no apparent historical recombination. To determine these intervals, we first examined the pairwise $D^{\prime}$ values. A pairwise $D^{\prime}$ value of 1 indicates that no more than three of the four possible haplotypes are observed (Leitersdor et al. 1989) and indicates the rarity of recombination between a pair of SNPs. We first searched for intervals in which all SNPs had pairwise $D^{\prime}>0.8$ and assumed that they constituted the minimum blocks. These intervals were then expanded by adding SNPs to the ends to find the longest intervals, as follows: The estimated haplotypes and their 95\% confidence intervals were bootstrapped before adding an SNP. If the haplotype frequencies after adding an SNP fell into the corresponding 95\% confidence intervals, we concluded that the added marker belonged to the same block. We repeated this procedure until we found that adding a marker led to a statistical change in the haplotype distribution. Based on this definition, we would anticipate that no apparent recombination events had occurred within a block.

We also calculated composite $\delta_{c}$, which is defined as half of the sum of the absolute value of all allelic frequency differences at a locus (Shriver et al. 1997): by payment of page charges. This article must therefore be hereby marked "advertisement" in accordance with 18 USC section 1734 solely to indicate this fact.

\section{REFERENCES}

Abecasis, G., Noguchi, E., Heinzmann, A., Traherne, J., Bhattacharyya, S., Leaves, N., Anderson, G., Zhang, Y., Lench, N., Carey, A., et al. 2001. Extent and distribution of linkage disequilibrium in three genomic regions. Am. J. Hum. Genet. 68: 191-197.

Antonarakis, S.E., Oettgen, P., Chakravarti, A., Halloran, S.L., Hudson, R.R., Feisee, L., and Karathanasis, S.K. 1988. DNA polymorphism haplotypes of the human apolipoprotein APOA1-APOC3-APOA4 gene cluster. Hum. Genet. 80: 265-273.

Blanton, S.H. and Chakavarti, A. 1987. A global test of linkage disequilibrium. Am. J. Hum. Genet. 41: A250.

Bonnardeaux, A., Davies, E., Jeunemaitre, Fery, I., Charu, A., Clauser, E., Tiret, L., Cambien, F., Corval, P., and Soubrier, F. 1994. Angiotensin II type 1 receptor gene polymorphisms in human essential hypertension. Hypertension 24: 63-69.

Cargill, M., Altshuler, D., Ireland, J., Skalar, P., Ardlie, K., Patil, N. Shaw, N., Lane, C., Lim, E., Kalyanaraman, N., et al. 1999. Characterization of single-nucleotide polymorphisms in coding regions of human genes. Nat. Genet. 22: 231-238.

Chakraborty, R. and Weiss, K.M. 1988. Admixture as a tool for finding linkage genes and detecting that difference from allelic association between loci. Proc. Natl. Acad. Sci. 85: 9119-9123.

Chakraborty, R., Kamboh, M.I., and Ferrell, R.E. 1991. 'Unique' alleles in admixed populations: A strategy for determining 'hereditary' population differences of disease frequencies. Ethn. Dis. 1: 245-256.

Chakravarti, A., Buetow, K.H., Antonarakis, S.E., Waber, P.G., Boehm, C.D., and Kazazian, H.H. 1984. Nonuniform recombination within the human $\beta$-globin gene cluster. Am. J. Hum. Genet. 36: 1239-1258.

Clark, A.G., Weiss, K.M., Nickerson, D.A., Taylor, S.L., Buchanan, A., Stengard, J., Salomaa, V., Vartiainen, E., Perola, M., Boerwinkle, E., et al. 1998. Haplotype structure and population genetic inferences from nucleotide sequence variation in human lipoprotein lipase. Am. J. Hum. Genet. 63: 595-612. 2001. High-resolution haplotype structure in the human genome. Nat. Genet. 29: 229-232.

Dunning, A., Durocher, F., Healy, C., Teare, M., McBride, S., Carlomagno, F., Xu, C., Dawson, E., Rhodes, S., Ueda, S., et al. with distinct demographic histories. Am. J. Hum. Genet. 67: 1544-1554.

Erdmann, J., Riedel, K., Rohde, K., Folgmann, I., Wienker, T., Fleck, E., and Regitz-Zagrosek, V. 1999. Characterization of polymorphisms in the promoter of the human angiotensinogen
The publication costs of this article were defrayed in part

Daly, M.J., Rioux, J.D., Schaffner, S.F., Hudson, T.J., and Lander, E.S 2000. The extent of linkage disequilibrium in four populations 
II subtype 1 (AT1) receptor gene. Ann. Hum. Genet. 63: 369-374.

Fornage, M., Amos, C.I., Kardia, S., Sing, C.F., Turner, S.T., and Boerwinkle, E. 1998. Variation in the region of the angiotensin-converting enzyme gene influences interindividual differences in blood pressure levels in young white males. Circulation 97: 1773-1779.

Halushka, M., Fan, J.-B., Bentley, K., Hsie, L., Weder, A., Cooper, R.S., Lipshutz, R., and Chakravarti, A. 1999. Patterns of single-nucleotide polymorphisms in candidate genes for blood pressure homeostasis. Nat. Genet. 22: 239-247.

Hill, W.G. and Robertson, A. 1968. Linkage disequilibrium in finite populations. Theor. Appl. Genet. 38: 226-231.

Inoue, I., Nakajima, T., Williams, C.S., Quackenbush, J., Puryear, R., Powers, M., Cheng, T., Ludwig, E.H., Sharma, A.M., Hata, A., et al. 1997. A nucleotide substitution in the promoter of human angiotensinogen is associated with essential hypertension and affects basal transcription in vitro. J. Clin. Invest. 99: 1786-1797.

Jeffreys, A.J., Kauppi, L., and Neumann, R. 2001. Intensely punctate meiotic recombination in the class II region of the major histocompatibility complex. Nat. Genet. 29: 217-222.

Jeunemaitre, X., Soubrier, F., Kotelevtsev, Y.V., Lifton, R.P., Williams, C.S., Charu, A., Hunt, S.C., Hopkins, P.N., Williams, R.R., Lalouel, J.M., et al. 1992. Molecular basis of human hypertension: Role of angiotensinogen. Cell 71: 169-180.

Johnson, G.C.L., Esposito, L., Barratt, B.J., Smith, A.N., Heward, J., Genova, G.D., Ueda, H., Cordell, H.J., Eaves, I.A., Dudbridge, F., et al. 2001. Haplotype tagging for the identification of common disease genes. Nat. Genet. 29: 233-237.

Jorde, L.B. 2000. Linkage disequilibrium and the search for complex disease genes. Genome Res. 10: 1435-1444.

Keavney, B., McKenzie, C., Parish, S., Palmer, A., Clark, S., Youngman, L., Delepine, M., Lathrop, M., Peto, R., and Collins, R. 2000. For the ISIS Collaborators. Large-scale test of hypothesised associations between the angiotensin-convertingenzyme insertion/deletion polymorphism and myocardial infarction in about 5000 cases and 6000 controls. Lancet 355: 434-444.

Kruglyak, L. 1999. Prospects for whole-genome linkage disequilibrium mapping of common disease genes. Nat. Genet. 22: $139-144$

Lander, E.S. and Schork, N.J. 1994. Genetic dissection of complex traits. Science 265: 2037-2048.

Leitersdor, E., Chakravarti, A., and Hobbs, H.H. 1989. Polymorphic DNA haplotypes at the LDL receptor locus. Am. J. Hum. Genet. 44: 409-442.

Lowontin, R.C. 1964. The interaction of selection and linkage. I. General considerations. Genetics 49: 49-67.

O'Malley, J.P., Maslen, C.L., and Illingworth, D.R. 1999. Angiotensin-converting enzyme and cardiovascular disease risk. Curr. Op. Lipid. 10: 407-415.

Patil, N., Berno, A.J., Hinds, D.A., Barrett, W.A., Doshi, J.M., Hacker, C.R., Kautzer, C.R., Lee, D.H., Marjoribanks, C., McDonough, D.P., et al. 2001. Blocks of limited haplotype diversity revealed by high-resolution scanning of human chromosome 21 . Science 294: $1719-1723$.

Province, M.A., Boerwinkle, E., Chakravarti, A., Cooper, R., Fornage, M., Leppert, M., Risch, N., and Ranade, K. 2000. Lack of association of the angiotensinogen-6 polymorphism with blood pressure levels in the comprehensive NHLBI Family Blood Pressure Program. J. Hypertens. 18: 867-875.

Reich, D.E., Cargill, M., Bolk, S., Ireland, J., Sabeti, P.C., Richter, D.J., Lavery, T., Kouyoumjia, R., Farhadian, S.F., Ward, R., et al.. 2001. Linkage disequilibrium in the human genome. Nature 411: 199-204.

Rieder, M.J., Taylor, S.L., Clark, A.G., and Nickerson, D.A. 1999. Sequence variation in the human angiotensin converting enzyme. Nat. Genet. 22: 59-62.

Rioux, J.D., Daly, M.J., Silverberg, M.S., Lindbald, K., Steinhart, H., Cohen, Z., Delmonte, T., Kocher, K., Miller, K., Guschwan, S., et al. 2001. Genetic variation in the 5 q31 cytokine gene cluster confers susceptibility to Crohn disease. Nat. Genet. 29: 223-228.

Risch, N.J. 2000. Searching for genetic determinants in the new millennium. Nature 405: 847-856.

Sachidanandam, R., Weissman, D., Schmidt, S.C., Kakol, J.M., Stein, L.D., Marth, G., Sherry, S., Mullikin, J.C., Mortimore, B.J., Willey, D.L., et al. 2001. A map of human genome sequence variation containing 1.42 million single nucleotide polymorphisms. Nature 409: 928-933.

Shriver, M.D., Smith, M.W., Jin, L., Marcini, A., Akey, J.M., Deka, R., and Rerrel, R.E. 1997. Ethnic-affiliation estimation by use of population-specific DNA markers. Am. J. Hum. Genet. 60: $957-964$

Soubrier, F., Nadaud, S., and Williams, T.A. 1994. Angiotensin I converting enzyme gene: Regulation, polymorphism and implications in cardiovascular diseases. Eur. Heart J. 15: 24-29.

Stephens, M., Smith, N.J., and Donnelly, P. 2001. A new statistical method for haplotype reconstruction from population data. Am. J. Hum. Genet. 68: 978-989.

Svetky, L.P., Moore, T.J., Simons-Morton, D.G., Appel, L.J., Bray, G.A., Sacks, F.M., Ard, J.D., Mortensen, R.M., Mitchell, S.R., Conlin, P.R., et al. 2001. For the DASH Collaborative Group. Angiotensinogen genotype and blood pressure response in the Dietary Approaches to Stop Hypertension (DASH) study. J. Hypertens. 19: 1949-1956.

Taillon-Miller, P., Bauer-Sardina, I., Saccone, N., Putzel, J., Laitinen, T., Cao, A., Kere, J., Pilia, G., Rice, J., and Kwok, P. 2000. Juxtaposed regions of extensive and minimal linkage disequilibruim in human Xq25 and Xq28. Nat. Genet. 25: $246-247$.

Templeton, A.R., Clark, A.G., Weiss, K.M., Nickerson, D.A., Boerwinkle, E., and Sing, C.F. 2000. Recombinational and mutational hotspots within the human lipoprotein lipase gene. Am. J. Hum. Genet. 66: 69-83.

Thompson, E.A., Deeb, S., Walker, S., and Motulsky, A.G. 1988. The detection of linkage disequilibrium between closely linked markers: RFLPs of the olipoprotein genes. Am. J. Hum. Genet. 42: $113-124$

Tishkoff, S.A., Dietzsch, E., Speed, W., Pakstis, A.J., Kidd, J.R., Cheung, K., Bonne-Tamir, B., Santachiara-Benerecetti, A.S, Moral, P., Krings, M., et al. 1996. Global patterns of the linkage disequilibrium at the CD4 locus and modern human origins. Science 271: 1380-1387.

Weir, B.S. 1996. Genetic data analysis II. Sinauer Associates, Sunderland, MA.

Wright, A.F., Carothers, A.D., and Piratsu, M. 1999. Population choice in mapping genes for complex diseases. Nat. Genet. 23: $397-404$.

Wright, W. 1931. Evolution in Mendelian populations. Genetics 16: $97-159$.

Zhu, X., McKenzie, C., Forrester, T., Nickerson, D.A., Cooper, R.S., and Rieder, M.J. 2000. Localization of a small genomic region associated with elevated ACE. Am. J. Hum. Genet. 67: 1144-1153.

Zhu, X., Bouzekri, N., Southam, L., Cooper, R.S., Adeyemo, A., McKenzie, C.A., Luke, A., Chen, G., Elston, R.C., and Ward, R. 2001. Linkage and association analysis of angiotensin I-converting enzyme (ACE) gene polymorphisms with ACE concentration and blood pressure. Am. J. Hum. Genet. 68: $1139-1148$.

\section{WEB SITE REFERENCES}

http://www.ncbi.nlm.nih.gov/Omim; Online Mendelian Inheritance in Man (OMIM)

Received March 22, 2002; accepted in revised form October 22, 2002. 


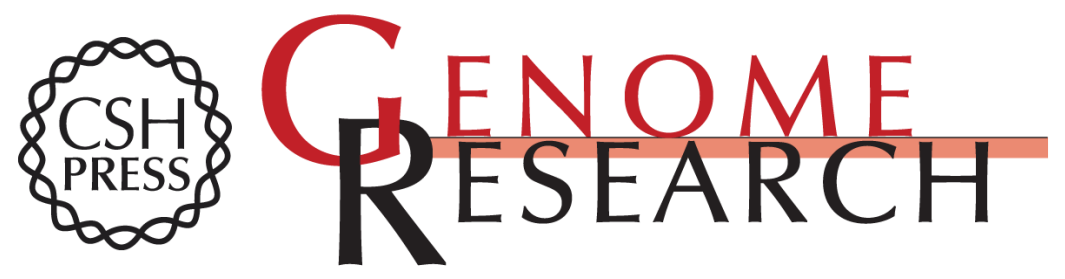

\section{Linkage Disequilibrium and Haplotype Diversity in the Genes of the Renin -Angiotensin System: Findings From the Family Blood Pressure Program}

Xiaofeng Zhu, Denise Yan, Richard S. Cooper, et al.

Genome Res. 2003 13: 173-181

Access the most recent version at doi:10.1101/gr.302003

Supplemental http://genome.cshlp.org/content/suppl/2003/01/17/GR-3020R.DC1
Material

References This article cites 43 articles, 9 of which can be accessed free at:

http://genome.cshlp.org/content/13/2/173.full.html\#ref-list-1

\section{License}

Email Alerting

Receive free email alerts when new articles cite this article - sign up in the box at the Service top right corner of the article or click here.

\section{Affordable, Accurate Sequencing.}

